\title{
Risk-Based Decision Support Model for the Optimal Operation of a Smart Energy Distribution Company for Enabling Emerging Resources
}

\author{
S. Muhammad Bagher Sadati \\ and Jamal Moshtagh \\ University of Kurdistan, Iran \\ bagher_sadati@yahoo.com; \\ j.moshtagh@uok.ac.ir
}

\author{
Miadreza Shafie-khah \\ C-MAST/UBI, Covilha, \\ Portugal \\ miadreza@gmail.com
}

\author{
João P. S. Catalão \\ INESC TEC and FEUP, Porto, \\ C-MAST/UBI, Covilha, and \\ INESC-ID/IST-UL, Lisbon, Portugal \\ catalao@fe.up.pt
}

\begin{abstract}
In this paper, a risk-based decision support model is developed for a smart energy distribution company, enabling emerging resources like renewable energy sources, electric vehicles and demand response programs in a holistic approach. Because of the inherent uncertainties of these emerging resources, the conditional value-at-risk (CVaR) method is adopted to restrict the distribution company's risk. A risk aversion parameter sensitivity analysis is also provided on the optimal operation of the smart energy distribution company. The proposed model is thoroughly tested on a 15-bus distribution grid system, and the numerical results prove the effectiveness of the model in risk management.
\end{abstract}

\section{Introduction}

\subsection{Motivation and Literature Review}

The planning and operation of a smart energy distribution company (SDISCO) will face new challenges with the increasing the presence of electric vehicles (EVs), because of the uncertainties of charging and discharging modes.

If suitable charging/discharging schedule is not used, the presence of EVs may yield improper results such as an increase of losses [1], unbalancing of loads [2], voltage drops [3], increase of total harmonic distortion [4], and decrease of cable and transformers life [5]. Thus, it is necessary to apply smart charging/discharging scheduling and also to build the parking lot (PL) in the SDISCO for using the vehicleto-grid (V2G) program [6], [7].

Moreover, according to the result of some studies such as [8], charging EVs only with traditional power plants creates inappropriate environmental impacts.
Thus, it is inevitable that renewable energy resources (RERs) will be used along with these types of power plants. In addition, demand response (DR) programs have become one of the most cost-effective and efficient solutions for reducing the load of a SDISCO, especially when the upstream network has some problems for supplying the load. For a more accurate assessment of DR programs, a proper model is needed.

In [9], an economic model is presented for the responsive load based on the price elasticity of demand, electricity price, as well as the incentive and the penalty values.

In most cases, the SDISCO's purpose is to maximize the profits or minimize the costs while minimizing the associated risk. This risk has arisen from the uncertainties of load, electricity price, etc. Usually, the risk management is accomplished by means of so-called risk measures. The profit variance, shortfall probability, expected shortfall, value-at-risk $(\mathrm{VaR})$ and conditional value-at-risk $(\mathrm{CVaR})$ are some examples of the risk measures [10].

The operational scheduling of SDISCO has been evaluated in different studies over the past few years; however, a simultaneous investigation of the operational scheduling of SDISCO in the presence of EVs PL, while considering DR programs and risk index, has not been carried out. It can be noted that the operator of the SDISCO owns EVs PL, RERs, and it is responsible for implementing DR programs. In fact, modeling this framework and presenting a precise mathematical model is the main reason for writing this paper.

\subsection{Contributions and Paper Organization}

In this paper, a new risk-based model is presented for the optimal operation of a SDISCO considering RERs and PL along with their uncertainties, as well as incentive-based and price-based DR programs. 
Uncertainties are also modeled with probability distribution function (PDF). Therefore, the novel contributions of this paper are twofold:

1. Presenting a new risk-based model for the optimal operation of a SDISCO, considering simultaneously RERs, EVs, and their uncertainties, as well as DR programs in a holistic approach.

2. Providing a risk aversion parameter sensitivity analysis on the optimal operation of the SDISCO.

The rest of the paper is organized as follows. The DR model and risk management are explained in section 2. The formulation of the proposed model is explained in section 3 . Section 4 is dedicated to the problem solving process. Numerical results are discussed in section 5. Finally, section 6 concludes the paper.

\section{DR Model and Risk Management}

\subsection{DR Model}

The demand sensitivity respect to the price is defined as Elasticity [9].

$E=\frac{\operatorname{Pr}_{0}}{P_{0}} \cdot \frac{\partial P}{\partial \operatorname{Pr}}$

Based on (1), the load divided to two type: singleperiod loads and multi-period loads. The first type, known as self-elasticity because the value is negative, while the second type is known as cross-elasticity, in which the value is positive.

$$
\begin{aligned}
& E(t, t) \leq 0 \\
& E\left(t, t^{\prime}\right) \geq 0
\end{aligned}
$$

DR programs are divided into two main groups involving incentive-based and price-based DR programs. Price-based DR programs are voluntary programs (time of use (TOU), real time pricing (RTP), critical peak pricing (CPP)); however, the incentivebased DR programs include voluntary programs (emergency DR program (EDRP), direct load control (DLC)), mandatory programs (interruptible/curtailable programs (I/C), capacity market program), and market clearing programs (demand bidding (DB), and ancillary services market (AS)). So, for the load economic model we will have [9]:

$$
P_{t}=P_{t}^{0} \times\left\{1+\sum_{t^{\prime} \in \mathrm{T}} \frac{\operatorname{Pr}_{t^{\prime}}-\operatorname{Pr}_{t^{\prime}}^{0}+A_{t^{\prime}}+P E N_{t^{\prime}}}{\operatorname{Pr}_{t^{\prime}}^{0}} \times E\left(t, t^{\prime}\right)\right\}
$$

According to (3), it is clear that the consumption of customers $\left(P_{t}\right)$ will change to obtain the maximum profit. The SDISCO is responsible for implementing DR programs. Despite many benefits of DR, there is an additional cost. These costs $\left(\mathrm{C}^{\mathrm{DR}}\right)$ are presented in (4).

$$
C^{D R}=\left(A_{t} \times\left(P_{t}^{0}-P_{t}\right)\right)-P E N_{t} \times\left(P_{t}^{c o n}-\left(P_{t}^{0}-P_{t}\right)\right)
$$

\subsection{Risk Management}

In order to manage the risk of SDISCO's operation resulting from the uncertain behavior of EVs, RERs, and CVaR, a well-known risk assessment technique is employed. CVaR is formulated in (5) [10].

$$
\begin{aligned}
& B_{s}=\zeta-\frac{1}{1-\alpha} \sum_{s=1}^{S N} \rho_{s} \eta_{s} \\
& -B_{s}+\zeta-\eta_{s} \leq 0 \\
& \eta_{s} \geq 0
\end{aligned}
$$

Parameter $\alpha$ is the confidence level, and it is generally between 0.90 and 0.99 . In this paper, it is set to 0.95 .

\section{Problem Formulation}

In this section, a risk-based model is presented for the optimal operation of a SDISCO. The aim of the objective function is the maximization of the SDISCO's profit. The operator of the SDISCO owns EVs PL, RERs, and it is responsible for implementing DR programs. Thus, the SDISCO should provide the needed energy for customers and for charging the EVs.

This energy is purchased from the wholesale market. The SDISCO can also use renewable energy generation. Of course, a part of the needed energy is prepared for customers at on-peak periods by encouraging the $\mathrm{EV}$ owners and paying proper incentives, by taking the capability of V2G into account. In addition, the SDISCO must pay the battery depreciation cost to the EVs owners due to the participation in the $\mathrm{V} 2 \mathrm{G}$ mode. Therefore, the objective function is composed of as (6).

The objective function includes the revenue from selling the energy to EV owners (the first term), the revenue from selling the energy to the customers (the second term), the cost of energy purchased from the wholesale market (the third term), the cost of energy purchased from the EV owners (the fourth term), the cost of battery depreciation (the fifth term), and the cost of implementation of PBDR and IBDR programs (the sixth and seventh terms, respectively). 
It should be noted that the time interval in this paper is 1 hour $(\mathrm{t}=1)$ and a distribution system for probing the proposed model is considered over a 24 -h period of time.

$$
\begin{aligned}
& O F=(1-\beta) \times \sum_{s=1}^{N s} \rho_{s}\left(\begin{array}{l}
\sum_{n=1}^{N} \sum_{t=1}^{24} P_{n, t, s}^{c h} \times \operatorname{Pr}_{t}^{c h}+\sum_{b=2}^{N b} \sum_{t=1}^{24} P_{b, t}^{L, D R} \times \operatorname{Pr}_{t}^{L, D R} \\
-\sum_{S b=1}^{N S b} \sum_{t=1}^{24} P_{S b, t}^{W h} \times \operatorname{Pr}_{t}^{W h} \\
-\sum_{n=1}^{N} \sum_{t=1}^{24} P_{n, t, s}^{d c h} \times \operatorname{Pr}_{t}^{d c h} \\
-\sum_{n=1}^{N} \sum_{t=1}^{24} P_{n, t, s}^{d c h} \times C^{c d} \\
-\sum_{b=2}^{N b} \sum_{t=1}^{24}\left(A_{t}\left(P_{b, t}^{L}-P_{b, t}^{L, D R}\right)\right) \\
+\sum_{b=2}^{N b} \sum_{t=1}^{24}\left(P E N_{t}\left(P_{b, t}^{c o n}-P_{b, t}^{L}+P_{b, t}^{L, D R}\right)\right)
\end{array}\right) \\
& +\beta \times\left(\zeta-\frac{1}{1-\alpha} \sum_{s=1}^{S N} \rho_{s} \eta_{s}\right)
\end{aligned}
$$

In order to achieve this goal (i.e., maximization of the profit), several constraints should be considered including the constraints of wind and PV generation, line current, bus voltage, and power balance.

$$
\begin{aligned}
& 0 \leq P_{b, t, s}^{W} \leq P^{W, \max } \\
& 0 \leq P_{b, t, s}^{P V} \leq P^{P V, \max }
\end{aligned}
$$

Based on (7) and (8), the wind and PV generation in each scenario must be limited to the minimum and maximum generation.

The optimal power flow must satisfy the limitations assigned by the constraints of bus voltages and branch flows.

Due to (9), because of the line thermal capacity, the maximum value of each branch current is limited by the conductor specifications, i.e., resistance and reactance of the branch. Also, according to (10), the voltage of each bus and the current of each branch should be in the range.

The maximum and minimum values of the voltage in each bus are 1.05 and 0.95 p.u., respectively.

$$
\begin{aligned}
& I_{b, t, s} \leq I^{b, \max } \\
& V_{\text {min }}=0.95 \leq V_{b, t, s} \leq V^{\max }=1.05
\end{aligned}
$$

The power produced by the traditional power plant and RES must be equal to the power consumption by consumers. Also, PL acts as a source at the on-peak period and as a load at the off-peak or mid-peak period. Hence, the power balance is described in (11).
$P_{S b, t}^{W h}+P_{b, t, s}^{W W}+P_{b, t, s}^{P V}+\sum_{\mathrm{N}} P_{n, t, s}^{d c h}=P_{b, t}^{\mathrm{LDR}}+P_{t, s}^{L \text { Lss }}+\sum_{\mathrm{N}} P_{n, t, s}^{c h}$

Moreover, a proper smart charging/discharging schedule of EVs should be considered. In fact, considering the arrival time and the initial state of energy (SOE) of the EVs, the charging/discharging plan should be able to meet the requirement of the EV owners, which is the desired SOE at the departure time. Minimum and maximum of SOE, SOE of EVs at each time [11], charging/discharging rate and desired SOE of EVs are the constraints of this schedule.

According to (12), the total SOE of the EVs cannot exceed the minimum and maximum SOE of each EV. Also, according to (13.a) and (13.b), the SOE of EVs at each hour appertains many factors including the remaining SOE of the EVs from the previous hour, the amount of power exchanged with the SDISCO and the $\mathrm{PL}$, the charge/discharge efficiency, and the initial SOE of EVs.

$$
\begin{array}{ll}
S O E_{n, t, s}^{\min } \leq S O E_{n, t, s} \leq S O E_{n, t, s}^{\max } & \forall \mathrm{n}, \mathrm{t}, \mathrm{s} \\
S O E_{\mathrm{n}, \mathrm{s} s}=S O E_{\mathrm{n}, \mathrm{t}-1, \mathrm{~s}}+\left(P_{n, t, s}^{c h} \times \eta^{d h}\right)-\left(\frac{P_{n, t, s}^{d c h}}{\eta^{d c h}}\right) & \forall n, \mathrm{t} \succ \mathrm{t}^{\mathrm{w},}, \mathrm{s} \\
S O E_{\mathrm{n}, \mathrm{s}}=\mathrm{SOE}_{\mathrm{n}, \mathrm{t}, \mathrm{s}}^{\mathrm{arv}}+\left(P_{n, t, s}^{c h} \times \eta^{c h}\right)-\left(\frac{P_{n, t, s}^{d c h}}{\eta^{d c h}}\right) & \forall n, \mathrm{t}=\mathrm{t}^{\mathrm{w},}, \mathrm{s}
\end{array}
$$

The amount of power purchased by each EV from the PL is limited to its maximum value. Further, the amount of power that each EV can sell to the PL is also limited to a maximum value. These two constraints are shown in (14) and (15), respectively.

$$
\begin{array}{ll}
0 \leq P_{n, t, s}^{c h} \leq P_{n}^{\max } & \forall \mathrm{n}, \mathrm{t}, \mathrm{s} \\
0 \leq P_{n, t, s}^{D c h} \leq P_{n}^{\max } & \forall \mathrm{n}, \mathrm{t}, \mathrm{s}
\end{array}
$$

Furthermore, according to (16), the management of charging/discharging the EVs should be accurate in such a way that at the departure time, the SOE of EVs reaches the desired value.

$$
S O E_{n, t, s}=\mathrm{SOE}_{\mathrm{n}, \mathrm{t, \textrm {s }}}^{\mathrm{dep}} \quad \forall \mathrm{n}, \mathrm{t}^{\mathrm{dep}}, \mathrm{s}
$$

Finally, based on (17), the charging and discharging of EVs cannot occur at the same time. It is noted that for the power flow, in this paper, a linear model for radial distribution systems is used, which is extracted from [11]. The framework of the proposed model is shown in Figure 1.

$X_{n, t, s}^{C h}+X_{n, t, s}^{d c h} \leq 1 \quad \forall \mathrm{n}, \mathrm{t}, \mathrm{s}$ 
Inputs:

1. $\mathrm{PV}$ and wind unit generation.

2. The required energy of each EVs.

3. Specification of SDISCO such as R and $\mathrm{X}$ of line, Load Data.

4. Implementation of PBDR and IBDR programs.

Objective Function:

Maximization the profit of SDISCO

Decision Variables: Power purchased from wholesale market, Power purchased/sold from/to EVs (power exchange with EVs).

Constraints: Linear Power flow, RERs generation, Bus voltage and Line current, Power Balance, SOE ( $\mathrm{min} / \mathrm{max} /$ desired $)$ and charging/discharging rate.

Outputs:

1. Charging and discharging schedule.

2. Power exchange with EVs.

3. Optimal operation of SDISCO and EVs.

Figure 1. Framework of the proposed model.

\section{Problem Solving Process}

Since this problem has different uncertainties, stochastic programming is used to solve the objective function. The following five uncertainties are considered in this paper:

- Uncertainty of wind generation: Because of the intermittency of wind speed, many experiments prove that stochastic wind speed in many regions roughly pursues a Weibull PDF. The output of the wind unit can be obtained through the linear relationship between the wind speed and the wind turbine output [12].

- Uncertainty of solar generation: Predominantly illumination intensity affects the output of the PV unit. In [12], it is shown that the distribution of solar irradiance is characterized by using a Weibull PDF. The output of PV can be obtained through the linear relationship between irradiance and photovoltaic array output.

- Uncertainty of the arrival time of EVS.

- Uncertainty of the departure time of EVs.

- Uncertainty of the initial SOE of EVS.

Obtaining sufficient historical data for determining the exact PDF of three uncertainties of EVs, i.e., arrival time, departure time and initial SOE, is very difficult.
However, most of the studies have reasonably suggested that a truncated Gaussian distribution PDF can be used [11]. A scenario tree of all uncertainty is generated with the Monte Carlo method. Then, the scenarios are reduced with the concept of Kantorovich distance (K-distance).

Moreover, there are the binary and integer decision variables in the linear model. By considering all the relations, the proposed model is a Mixed-Integer Linear Programming (MILP) problem. Therefore, in this paper, the simulations are carried out through CPLEX solver of GAMS. The simulation has been implemented in a laptop with Core i7 up to $3.5 \mathrm{GHz} \mathrm{CPU}$ and $12 \mathrm{~GB}$ of RAM.

\section{Numerical Results}

To evaluate the proposed model, a 15-bus distribution system is considered over a 24 -h period of time, as illustrated in Figure 2.

The required data, such as load, resistance and reactance of branches, and the maximum line current limit of this test system, are taken from [13]. The required specifications of wind and PV units are summarized in Table 1 [12].

The modified details of EVs' probability distributions are expressed in Table 2 [11]. It is considered that 100 EVs are parked in the PL. The power factor of the customers and renewable units are 0.95 lagging and 1 , respectively.

The EVs' data are explained in Table 3 [7]. The price elasticity of the demand is considered as listed in Table 4 [9].

In order to study the optimal operation, time of use (TOU), capacity market programs (CAP) and combined TOU and CAP are considered, as presented in Table 5. The hourly prices of the energy market are extracted from [14]. Also, it is assumed that $20 \%$ of customers participate in the DR programs.

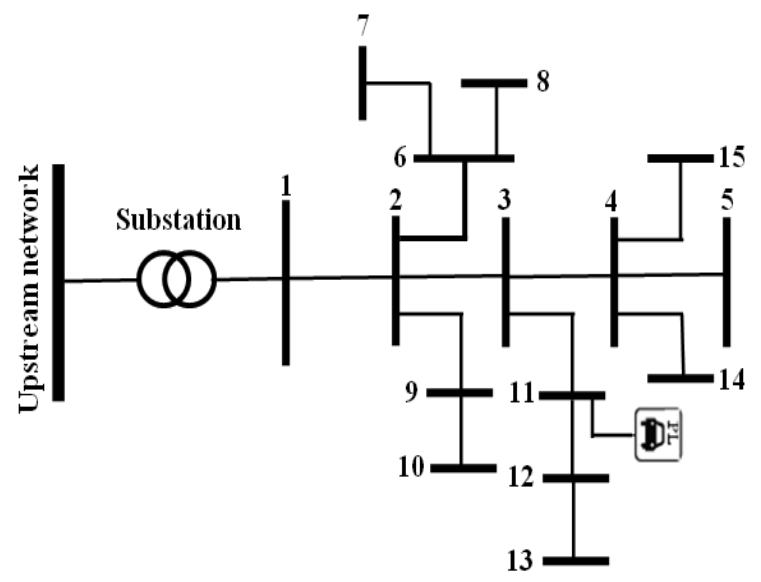

Figure 2. The 15-bus distribution system. 
Table 1. Considered data for PV and wind units.

\begin{tabular}{|c|c|c|c|c|c|c|}
\hline \multicolumn{7}{|c|}{ Wind unit } \\
\hline $\begin{array}{l}\text { size } \\
(\mathrm{kW})\end{array}$ & bus & $\begin{array}{l}\text { shape } \\
\text { index }\end{array}$ & $\begin{array}{l}\text { scale } \\
\text { index }\end{array}$ & $\begin{array}{l}\text { cut-in } \\
\text { speed } \\
(\mathrm{m} / \mathrm{s})\end{array}$ & $\begin{array}{c}\text { nominal } \\
\text { speed } \\
(\mathrm{m} / \mathrm{s})\end{array}$ & $\begin{array}{l}\text { cut- } \\
\text { out } \\
\text { speed } \\
(\mathrm{m} / \mathrm{s})\end{array}$ \\
\hline 200 & 12 & 2 & 6.5 & 4 & 14 & 25 \\
\hline \multicolumn{7}{|c|}{ PV unit } \\
\hline $\begin{array}{l}\text { size } \\
(\mathrm{kW})\end{array}$ & bus & $\begin{array}{l}\text { shape } \\
\text { index }\end{array}$ & $\begin{array}{l}\text { scale } \\
\text { index }\end{array}$ & \multicolumn{3}{|c|}{$\begin{array}{l}\text { rated illumination intensity } \\
\left(\mathrm{w} \cdot \mathrm{m}^{2}\right)\end{array}$} \\
\hline 200 & 12 & 1.8 & 5.5 & \multicolumn{3}{|c|}{1000} \\
\hline
\end{tabular}

Table 2. Probability Distribution of EVs.

\begin{tabular}{|c|c|c|c|c|}
\hline & Mean & $\begin{array}{c}\text { Standard } \\
\text { Deviation }\end{array}$ & Min & Max \\
\hline Initial SOE(\%) & 50 & 25 & 30 & 60 \\
\hline $\begin{array}{c}\text { Arrival Time } \\
\text { (h) }\end{array}$ & 8 & 3 & 7 & 10 \\
\hline $\begin{array}{c}\text { Departure } \\
\text { Time (h) }\end{array}$ & 20 & 3 & 18 & 24 \\
\hline
\end{tabular}

Table 3. Required specification of EVs.

\begin{tabular}{|c|c|c|c|c|c|}
\hline$\eta_{\mathrm{Ch}}$ & $90 \%$ & $\begin{array}{c}\text { Battery capacity } \\
(\mathrm{kWh})\end{array}$ & 50 & $\begin{array}{c}\mathrm{SOE}^{\min } \\
(\mathrm{kWh})\end{array}$ & 7.5 \\
\hline$\eta_{\mathrm{Dch}}$ & $95 \%$ & $\mathrm{P}^{\max }$ & 10 & $\begin{array}{c}\mathrm{SOE} \\
(\mathrm{kWh})\end{array}$ & 45 \\
\hline $\begin{array}{c}\mathrm{SOE}^{\text {dep }} \\
(\mathrm{kWh})\end{array}$ & 45 & $\mathrm{C}^{\mathrm{cd}}(\$ / \mathrm{MWh})$ & 30 & $\mathrm{PL}$ bus & 11 \\
\hline
\end{tabular}

Table 4. Self and cross elasticity.

\begin{tabular}{|c|c|c|c|}
\hline & On-peak & Mid-peak & $\begin{array}{c}\text { Off- } \\
\text { peak }\end{array}$ \\
\hline $\begin{array}{c}\text { On-peak (10-14 and } \\
19-21)\end{array}$ & -0.1 & 0.016 & 0.012 \\
\hline $\begin{array}{c}\text { Mid-peak (8-9 and } \\
15-18)\end{array}$ & 0.016 & -0.1 & 0.01 \\
\hline $\begin{array}{c}\text { Off-peak (1-7 and } \\
22-24)\end{array}$ & 0.012 & 0.01 & -0.1 \\
\hline
\end{tabular}

Table 5. Considering case for PBDR and IBDR for the operational scheduling of the SDISCO.

\begin{tabular}{|c|c|c|c|}
\hline Program & $\begin{array}{c}\text { Electricity price } \\
\text { for load, } \\
\text { charging/discharging } \\
\text { EVs }(\$ / \mathrm{MWh})\end{array}$ & $\begin{array}{l}\text { Incentive } \\
\text { value } \\
(\$ / \mathrm{MWh})\end{array}$ & $\begin{array}{l}\text { Penalty } \\
\text { value } \\
\text { (\$/MWh) }\end{array}$ \\
\hline TOU & $\begin{array}{c}\text { off-peak : } 85.562, \\
\text { mid-peak: } 171.125 \text {, } \\
\text { on-peak: } 342.25\end{array}$ & 0 & 0 \\
\hline CAP & 171.125 flat rate & 150 & 50 \\
\hline $\begin{array}{c}\text { TOU+ } \\
\text { CAP }\end{array}$ & $\begin{array}{c}\text { off-peak : } 85.562, \\
\text { mid-peak: } 171.125 \text {, } \\
\text { on-peak: } 342.25\end{array}$ & 150 & 50 \\
\hline
\end{tabular}

In order to investigate the effectiveness of the proposed model, the results in two states, i.e., $\beta=0$ and $\beta=1$, are evaluated. Firstly, Table 6 shows the profit of the SDISCO in three mentioned DR programs. Based on Table 6, TOU is the best program in terms of profit. The amount of profit is reduced by increasing $\beta$.

Also, the energy purchased from the wholesale market, charging and discharging power of EVs and network losses are shown in Tables 7 to 10, respectively. According to these Tables, in each DR program, by taking the risk into account, i.e., $\beta=1$, the SDISCO is obliged to buy more energy from the wholesale market and thereby the profit is reduced. It is due to the less attendance of EVs in V2G modes for supplying customers by considering the risk. Also, by increasing the purchase of energy, the network losses increase.

Figures 3 to 5 show the smart charging/discharging EVs in the CAP, TOU and CAP+TOU programs, respectively. According to these figures, after the arrival time of the EVs, i.e., 7:00, the charging at the mid-peak periods starts. Then, at the first on-peak periods, the EVs are discharged, except at 13:00. In fact, at 13:00, since the price of discharging power of EVs is higher than the price of the wholesale market, the SDISCO prefers to provide power from the wholesale market.

By taking the risk into account, i.e., $\beta=1$, in each DR programs at these periods, EVs participate less in V2G mode due to less charging power at 7:00 to 9:00. At the second mid-peak periods, i.e., 15:00 to 18:00, the charging of EVs is continued. At this period, the highest power is $1 \mathrm{MW}$ that occur at 17:00 and 18:00. For two reasons, this amount of charging occurs. Firstly, most of EVs have been discharged at first on-peak periods. Secondly, the majority of EVs leave the PL at 20:00 (EVs are not allowed to charge at this time), with desired SOE i.e. $45 \mathrm{kWh}$. So, all EVs are charged with fully charging rate i.e. $10 \mathrm{kWh}$. Because the number of EVs in the range 20:00-24:00 is low and there is not enough time for charging the EVs, the amount of power injected to the SDISCO is zero during the second onpeak periods i.e. 19:00-21:00. Also, at the second offpeak periods, some EVs are also charged.

The optimal operation of the SDISCO for $\beta=0$ and $\beta=1$ is shown in Figures 6 and 7, respectively. According to Figures 6 and 7, from 7:00 to 9:00, due to the presence of EVs in the PL, the amount of power purchased from the wholesale market increases because of the charging of the EVs. However, at the first onpeak period, i.e., from 10:00 to 14:00, less energy is purchased from the wholesale market, because during this period the SDISCO uses the RERs generation and power purchased from EV owners for meeting the customers' demand, except at 13:00. 
Once again, at the second mid-peak periods i.e. 15:00 to 18:00, the power purchased from the wholesale market dramatically increases, because of the EVs had participated in the V2G mode at 10:00 to 14:00, and the majority of EVs leave the PL at 20:00 with the desired SOE i.e. $45 \mathrm{kWh}$.

During the second on-peak period, i.e., from 19:00 to 21:00, because EVs are not charging, the power purchased from the wholesale market decreases. Also, some EVs are parked until around 24:00, the smart charging/discharging program shifts the charge of some EVs to 22:00. Thus, at this hour, the power purchased from the wholesale network increases. Also, purchasing of power in the $\beta=0$ case is much less than in the $\beta=1$ case.

Finally, the effect of the risk aversion parameter, i.e., $\beta$, on the optimal operation of the SDISCO in terms of profit is shown in Table 11. As can be seen in Table 11 , the profit is reduced by increasing $\beta$. In fact, low/high levels of risk are associated with a high/low expected profit.

Table 6. The profit in different DR programs (\$).

\begin{tabular}{|c|c|c|}
\hline Program & with $\beta=0$ & with $\beta=1$ \\
\hline TOU & 2150.319 & 1874.467 \\
\hline CAP & 2022.048 & 1731.025 \\
\hline TOU + CAP & 1786.292 & 1513.738 \\
\hline
\end{tabular}

Table 7. The power purchased from the wholesale market (MW).

\begin{tabular}{|c|c|c|}
\hline Program & with $\beta=0$ & with $\beta=1$ \\
\hline TOU & 31.114 & 31.154 \\
\hline CAP & 29.878 & 30.069 \\
\hline TOU + CAP & 29.325 & 29.367 \\
\hline
\end{tabular}

Table 8. Charging power of EVs (MW).

\begin{tabular}{|c|c|c|}
\hline Program & with $\beta=0$ & with $\beta=1$ \\
\hline TOU & 5.547 & 3.417 \\
\hline CAP & 5.637 & 4.400 \\
\hline TOU + CAP & 5.491 & 3.414 \\
\hline
\end{tabular}

Table 9. Discharging power of EVs (MW).

\begin{tabular}{|c|c|c|}
\hline Program & with $\beta=0$ & with $\beta=1$ \\
\hline TOU & 2.706 & 0.885 \\
\hline CAP & 2.782 & 1.725 \\
\hline TOU + CAP & 2.658 & 0.882 \\
\hline
\end{tabular}

Table 10. Losses of SDISCO (MW).

\begin{tabular}{|c|c|c|}
\hline Program & with $\beta=0$ & with $\beta=1$ \\
\hline TOU & 0.633 & 0.982 \\
\hline CAP & 0.607 & 0.978 \\
\hline TOU + CAP & 0.611 & 0.954 \\
\hline
\end{tabular}

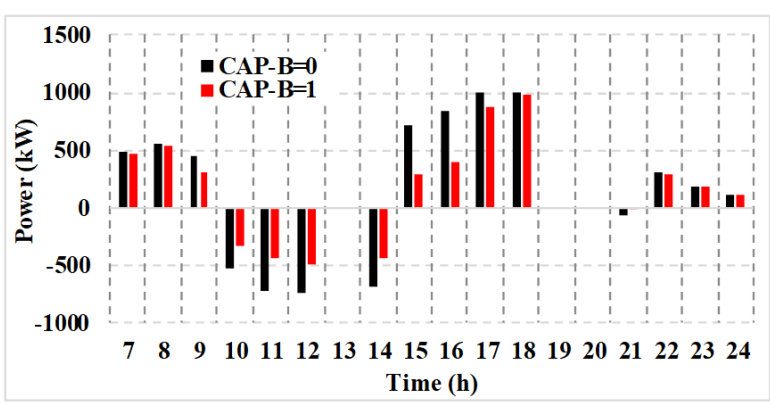

Figure 3. Smart charging/discharging scheduling of EVs in CAP programs.

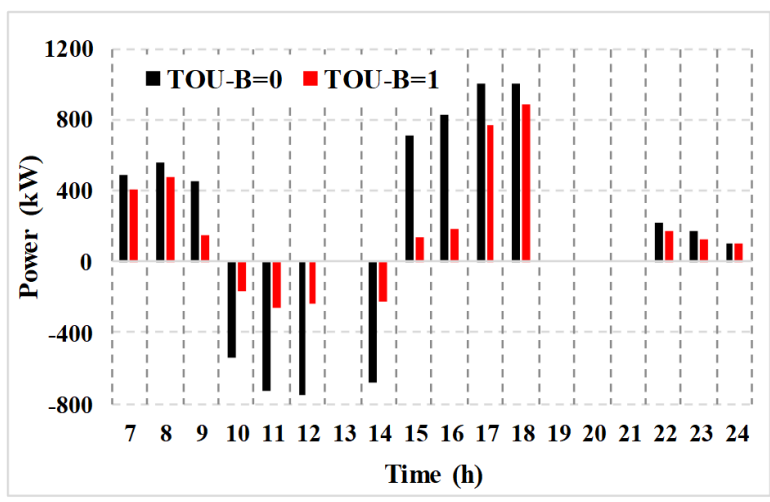

Figure 4. Smart charging/discharging scheduling of EVs in TOU programs.

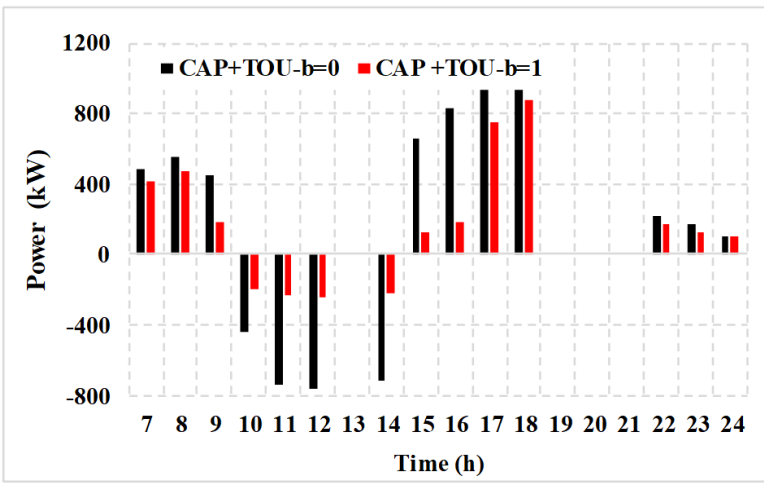

Figure 5. Smart charging/discharging scheduling of EVs in CAP+TOU programs. 


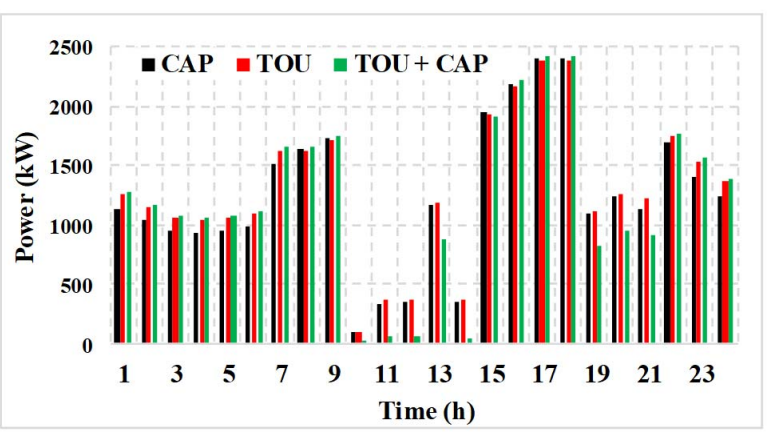

Figure 6. Optimal operation of the SDISCO in DR programs with $=0$.

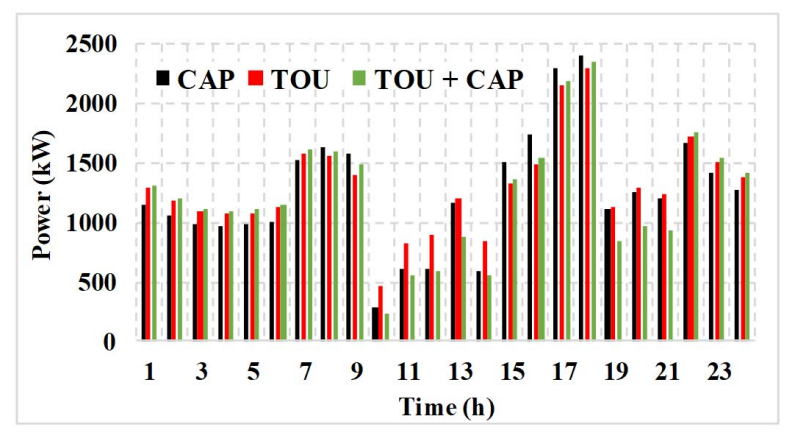

Figure 7. Optimal operation of the SDISCO in DR programs with $=1$.

Table 11. Risk aversion parameter effect on profits.

\begin{tabular}{|c|c|c|c|}
\hline$\beta$ & TOU & CAP & TOU + CAP \\
\hline 0 & 2150.319 & 2022.049 & 1786.293 \\
\hline 0.1 & 2122.733 & 1992.946 & 1759.037 \\
\hline 0.3 & 2067.563 & 1934.742 & 1704.527 \\
\hline 0.5 & 2012.393 & 1876.537 & 1650.016 \\
\hline 0.7 & 1957.222 & 1818.332 & 1595.505 \\
\hline 0.9 & 1902.052 & 1760.128 & 1540.994 \\
\hline 1 & 1874.467 & 1731.025 & 1513.738 \\
\hline
\end{tabular}

\section{Conclusions}

In this paper, the effect of EVs, RERs, incentivebased and price-based DR programs was investigated on the optimal operation of SDISCO. On this basis, by the smart charging/discharging scheduling of EVs (due to the V2G capability), the presence of RERs and the implementation of DR programs, the SDISCO achieved more profit. Also, CVaR was combined with the presented model to reduce the negative impacts of EVs and RERs uncertainties.
The following results were achieved from the numerical studies:

1. In the price-based DR program, i.e. TOU, the SDISCO achieved more profit.

2. By using a proper charging/discharging schedule of EVs, charging/discharging occurred during the off-peak or mid-peak / onpeak periods. Also, discharging could not occur at 13:00, because at this time the price of the EVs' discharging power was higher than that of the wholesale market.

3. By taking the risk into account, i.e. $\beta=1$, the profit was reduced due to the reduced presence of EVs in the V2G mode. In fact, by increasing $\beta$, a reduction in the profit occurred.

\section{Nomenclature}

\section{A. Indexes}

$b, b^{\prime} \quad$ Index for branch or bus

$F \quad$ Index for linear partitions in linearization

$S, s \quad$ Index for scenarios

$\mathrm{Sb} \quad$ Index for slack bus

$t, T \quad$ Index for time (hour)

$n, N \quad$ Index for EV number

B. Parameters

$\operatorname{Pr}_{0 t} \quad$ Initial electricity price at t-th hour (\$/kWh)

$\mathrm{Pr}_{t} \quad$ Electricity price at t-th hour after DR (\$/kWh)

$P^{L, D R} \quad$ Customer demand after DR $(\mathrm{kW})$

$P^{L} \quad$ Customer demand before DR $(\mathrm{kW})$

$E(t, t) \quad$ Self-elasticity

$E\left(t, t^{\prime}\right) \quad$ Cross-elasticity

$P_{0 t} \quad$ Initial demand value at $\mathrm{t}$-th hour $(\mathrm{kW})$

$P_{t} \quad$ Customer demand at t-th hour after DR $(\mathrm{kW})$

$P E N_{t} \quad$ Penalty of DR programs at $\mathrm{t}$-th hour (\$/kWh)

$A_{t} \quad$ Incentive of DR programs at $\mathrm{t}$-th hour $(\$ / \mathrm{kWh})$

$\rho_{s} \quad$ Probability of each scenario

$\mathrm{Pr}^{\mathrm{Ch}} \quad$ Price of energy purchased of SDISCO by EVs $(\$ / \mathrm{kWh})$

$P r^{L, D R} \quad$ Electricity price after DR $(\$ / \mathrm{kWh})$

$\mathrm{Pr}^{D c h} \quad$ Price of energy purchased of EVs by SDISCO $(\$ / \mathrm{kWh})$

$\mathrm{Pr}^{W h 2 G} \quad$ Price of purchased energy from the wholesale market $(\$ / \mathrm{kWh})$

$V_{\text {min }} \quad$ Minimum allowable voltage (V)

$V_{\max } \quad$ Maximum allowable voltage (V)

$P_{W, \max } \quad$ Maximum output power of wind unit $(\mathrm{kW})$

$P_{P V, \max } \quad$ Maximum output power of photovoltaic unit $(\mathrm{kW})$ 


\begin{tabular}{|c|c|}
\hline$S_{b}^{\max }$ & Maximum apparent power in bus b (kVA) \\
\hline$C^{c d}$ & Cost of equipment depreciation $(\$ / \mathrm{kWh})$ \\
\hline$S O E^{\min }$ & Minimum rate of SOE $(\mathrm{kWh})$ \\
\hline$S O E^{\max }$ & Maximum rate of SOE $(\mathrm{kWh})$ \\
\hline$\eta_{C h}$ & Charging efficiency $(\%)$ \\
\hline$\eta_{D c h}$ & Discharging efficiency $(\%)$ \\
\hline$S O E^{d e p}$ & $\begin{array}{l}\text { Desired final SOE of EV at departure } \\
\text { time }(\mathrm{kWh})\end{array}$ \\
\hline$S O E^{a r v}$ & $\begin{array}{l}\text { Initial SOE of EV at arrival time to the } \\
\text { PL (kWh) }\end{array}$ \\
\hline$P^{\max }$ & Charging or Discharging rate $(\mathrm{kWh})$ \\
\hline$S_{b}$ & Apparent power in bus $\mathrm{b}(\mathrm{kVA})$ \\
\hline$\alpha$ & Confidence level \\
\hline$\beta$ & Risk aversion parameter \\
\hline \multicolumn{2}{|c|}{ C. Variables } \\
\hline$P^{\text {Loss }}$ & Power loss of SDISCO $(\mathrm{kW})$ \\
\hline$P^{c h}$ & Transferred power to EVs $(\mathrm{kW})$ \\
\hline$P^{d c h}$ & Transferred power from EVs $(\mathrm{kW})$ \\
\hline$P^{W h 2 G}$ & $\begin{array}{l}\text { Transferred power from the wholesale } \\
\text { market to SDISCO }(\mathrm{kW})\end{array}$ \\
\hline$X^{c h}$ & $\begin{array}{l}\text { Binary variable that shows the charge } \\
\text { status of EVs }\end{array}$ \\
\hline$X^{d c h}$ & $\begin{array}{l}\text { Binary variable that shows the discharge } \\
\text { status of EVs }\end{array}$ \\
\hline$B_{s}$ & Profit in scenario $\mathrm{s}$ \\
\hline$\eta_{s}$ & $\begin{array}{l}\text { Auxiliary variable to calculate } \mathrm{CVaR} \text { in } \\
\text { scenario } \mathrm{s}\end{array}$ \\
\hline$\xi$ & Value-at-risk \\
\hline
\end{tabular}

\section{Acknowledgment}

J.P.S. Catalão acknowledges the support by FEDER funds through COMPETE 2020 and by Portuguese funds through FCT, under Projects SAICTPAC/0004/2015 - POCI-01-0145-FEDER-016434, and 02/SAICT/2017 - POCI-01-0145-FEDER-029803.

\section{References}

[1] M. S. ElNozahy and M. M. A. Salama, "A comprehensive study of the impacts of PHEVs on residential distribution networks", IEEE Trans. Sustain. Energy, vol. 5, no. 1, Jan. 2014, pp. 332-342.

[2] J. Y. Yong, V. K. Ramachandaramurthy, K. M. Tan, and N. Mithulananthan, "A review on the state-of-the-art technologies of electric vehicle, its impacts and prospects", Renew. Sustain. Energy Rev., vol. 49, Sep. 2015, pp. 365-385.

[3] H. Shareef, M. M. Islam, and A. Mohamed, "A review of the stage-of-the-art charging technologies, placement methodologies, and impacts of electric vehicles", Renew. Sustain. Energy Rev., vol. 64, Oct. 2016, pp. 403-420.
[4] S. Habib, M. Kamran, and U. Rashid, "Impact analysis of vehicle-to-grid technology and charging strategies of electric vehicles on distribution networks - A review", J. Power Sources, vol. 277, Mar. 2015, pp. 205-214.

[5] G. Razeghi, L. Zhang, T. Brown, and S. Samuelsen, "Impacts of plug-in hybrid electric vehicles on a residential transformer using stochastic and empirical analysis," J. Power Sources, vol. 252, Apr. 2014, pp. 277-285.

[6] N. Neyestani, M. Y. Damavandi, M. Shafie-Khah, J. Contreras, and J.P.S. Catalao, "Allocation of plug-in vehicles' parking lots in distribution systems considering network-constrained objectives", IEEE Trans. Power Syst., vol. 30, no. 5, Sep. 2015, pp. 2643-2656.

[7] S. Abapour, M. Abapour, K. Khalkhali, and S. M. Moghaddas-Tafreshi, "Application of data envelopment analysis theorem in plug-in hybrid electric vehicle charging station planning," IET Gener. Transm. Distrib., vol. 9, no. 7, Apr. 2015, pp. 666-676.

[8] R. Sioshansi and J. Miller, "Plug-in hybrid electric vehicles can be clean and economical in dirty power systems", Energy Policy, vol. 39, no. 10, Oct. 2011, pp. 6151-6161.

[9] H. A. Aalami, M. P. Moghaddam, and G. R. Yousefi, "Modeling and prioritizing demand response programs in power markets", Electr. Power Syst. Res., vol. 80, no. 4, Apr. 2010, pp. 426-435.

[10] A. J. Conejo, M. Carrión, and J. M. Morales, Decision Making Under Uncertainty in Electricity Markets, vol. 153. Boston, MA: Springer US, 2010.

[11] M. Shafie-khah, P. Siano, D.Z. Fitiwi, N. Mahmoudi, and J.P.S. Catalao, "An innovative two-level model for electric vehicle parking lots in distribution systems with renewable energy", IEEE Trans. Smart Grid, March. 2018, pp. 1506-1520.

[12] Z. Liu, F. Wen, and G. Ledwich, "Optimal siting and sizing of distributed generators in distribution systems considering uncertainties", IEEE Trans. Power Deliv., vol. 26, no. 4, Oct. 2011, pp. 2541-2551.

[13] A. Y. Abdelaziz, E.S. Ali, and S.M. Abd Elazim, "Optimal sizing and locations of capacitors in radial distribution systems via flower pollination optimization algorithm and power loss index", International Journal Engineering Science and Technology, vol. 19, no. 1, March. 2016, pp. 610-618.

[14] S. Talari, M.-R. Haghifam, and M. Yazdaninejad, "Stochastic-based scheduling of the microgrid operation including wind turbines, photovoltaic cells, energy storages and responsive loads", IET Gener. Transm. Distrib., vol. 9, no. 12 , Sep. 2015 , pp. $1498-1509$. 